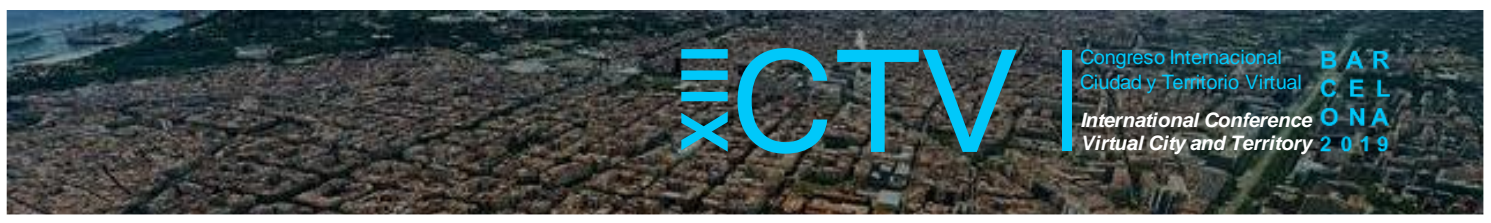

\title{
INTERVENCIONES DE MEJORA DE ACCESIBILIDAD EN LOS EDIFICIOS HISTÓRICOS DE BARCELONA
}

\author{
Cornadó, Còssima ${ }^{1 *}$; Vima Grau, Sara ${ }^{2}$; Martín García, Estefanía ${ }^{3}$ \\ Remisión inicial: 2019-06-04; Remisión definitiva: 2019-09-30; Publicación: 2019-12-21
}

Citación: Cornadó, C. et al. (2019). Intervenciones de mejora de accesibilidad en los edificios históricos de Barcelona. En XIII CTV 2019 Proceedings: XIII International Conference on Virtual City and Territory: "Challenges and paradigms of the contemporary city": UPC, Barcelona, October 2-4, 2019. Barcelona: CPSV, 2019, p. 8506. E-ISSN 2604-6512. DOI http://dx.doi.org/10.5821/ctv.8506

\section{Resumen}

Las intervenciones de rehabilitación para la mejora de la accesibilidad de los edificios residenciales existentes han sido una práctica habitual en los últimos años. Éstas han sido frecuentemente impulsadas por las administraciones en forma de ayudas públicas a la rehabilitación con el objetivo de mejorar las condiciones del parque residencial edificado complementando, de esta forma, aquellas intervenciones en el espacio público ya realizadas en el ámbito de la accesibilidad. Este tipo de intervenciones se hacen particularmente necesarias en centros históricos dónde abundan los edificios construidos siguiendo unos estándares en la edificación en materia de accesibilidad a menudo muy inferiores a los que se requieren hoy día.

El presente artículo estudia las posibles formas de mejorar la accesibilidad en los edificios históricos de Barcelona. En dicha categoría se incluyen los edificios construidos con técnicas constructivas históricas en Ciutat Vella, el Eixample y los antiguos municipios del llano de Barcelona, hoy en día integrados a la ciudad. En dichos edificios es habitual encontrar situaciones en las que la accesibilidad necesita ser mejorada: son frecuentes la existencia de más de tres plantas sin ascensor, escalones en los vestíbulos de acceso a los edificios y rellanos insuficientes en las plantas piso. Además, la morfología del edificio y de su estructura, a menudo, dificulta una intervención de mejora de la accesibilidad ya que los espacios comunes y patios suelen ser de dimensiones reducidas.

De cara al estudio, se analizan 20 casos de intervención real distribuidos en dicho ámbito con rehabilitaciones que afectan únicamente a los espacios comunes de los mismos. En él se detectan aquellas deficiencias iniciales de cara a la accesibilidad universal a diferentes niveles: con respecto al exterior, entre las plantas del edificio y en las propias plantas del edificio.

Se analizan las soluciones de rehabilitación adoptadas, tanto a nivel proyectual como tecnológico, que han sido compatibles con la morfología de los edificios existentes. A nivel proyectual se estudian cómo han sido solventadas situaciones como la elección de la ubicación para la instalación del nuevo ascensor, su desembarco en las plantas y la reconfiguración de los vestíbulos teniendo en cuenta reubicación de instalaciones y posible supresión de peldaños en los vestíbulos. A nivel tecnológico, se analizarán las soluciones constructivas adoptadas en el contacto con la edificación existente, la realización del foso del ascensor (apoyado en terreno o descolgado), posibles oberturas en muros, posibles recortes de bóvedas, los cerramientos de la caja del ascensor y entrega con cubierta.

Asimismo, se analizan las incompatibilidades detectadas entre la normativa y las posibilidades reales de la intervención, como la no obtención del máximo grado de accesibilidad posible debido a limitantes geométricos de la edificación o la disminución de las condiciones de ventilación e iluminación de las viviendas cuando el ascensor va situado en el patio. Asimismo, se verán que decisiones son aquellas que han llevado a un ajuste razonable de la solución adoptada.

Por último, se estudia cómo ha influido el contexto de protección patrimonial, diferente en cada caso, en la definición arquitectónica de los proyectos, tanto a nivel de soluciones constructivas, como de acabados seleccionados y elementos conservados.

Con ello, se pretende dar una visión general y a la vez detallada en profundidad de las casuísticas habituales en las intervenciones de mejora de accesibilidad en los edificios históricos de Barcelona que puede ser extrapolable a otras ciudades con centros históricos y edificaciones antiguas que necesitan ser actualizadas.

\footnotetext{
1 Universitat Politècnica de Catalunya - Barcelona Tech, http://orcid.org/0000-0003-0553-7176; ${ }^{2}{ }^{3}$ Universitat
} Politècnica de Catalunya - Barcelona Tech. *Correo de contacto: cossima.cornado@upc.edu 


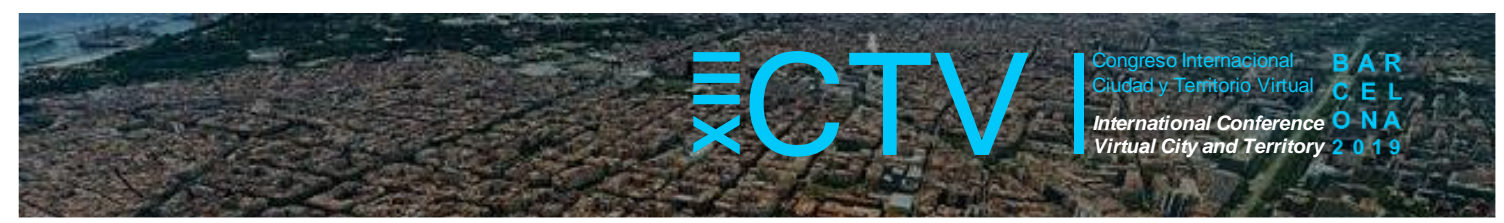

\section{Abstract}

In the last decades, interventions of rehabilitation of existing residential addressing improvements in accessibility have been a very usual practice. They have been commonly fostered by public administrations with the aim to complement the already frequent public investments in public space accessibility with funds that address the improvement of living conditions within the multi-family housing stock. This type of interventions is particularly necessary in historic centers, where building typologies in which the accessibility conditions are significantly below the current standards are abundant.

This paper presents a study of different forms of intervention of accessibility improvement in historical buildings in Barcelona. This category includes buildings constructed with historical techniques in Ciutat Vella, Eixample and some municipalities of the Barcelona plane that are nowadays part to the city of Barcelona. In these buildings, it is usual to find situations of lack of accessibility: more than three stories with no elevator installation, stairs in halls and lobby entrances to the buildings, as well as insufficient landings giving access to the dwellings. Moreover, the morphology of the buildings and their structure frequently challenge the implementation of an accessibility improving intervention because common spaces and inner courtyards use to have tiny dimensions.

The present study analyses 20 cases located in the area in which an intervention of rehabilitation affecting exclusively the common spaces has been implemented. Initial deficiencies regarding universal accessibility between and within the different levels are exposed: with respect to the exterior, between floors and within each of the floors.

The solutions adopted according to the morphology of existing buildings in each case are analyzed at design and technological level. From a design perspective, this study focuses on how several situations are addressed, such as the election of the suitable placing of the new elevator, its landing in each floor and the reconfiguration of lobbies according to the relocation of services and the possibly needed suppression of stairs and other architectonic barriers within the lobby. From a technological perspective, aspects related the constructive adopted solution in relation to contact with the existing building are described, such as the solution of the elevator pit (supported on the terrain or hanging), new openings in load-bearing walls, possible partial cropping of ceramic vaults, the adopted enclosure material of the lift and the solution of its contact with the roof.

Consecutively, this paper describes the detected incompatibilities between the current regulation framework and the possibilities of implementation on site. Usually, the impossibility to meet universal accessibility standards can be explained by the geometrical limits of existing buildings or the excessive reduction of ventilation and illumination conditions that the intervention would suppose (for example, when the elevator is to be located in inner courtyards). Decisions that have been determinant for the reasonable readjustment of the adopted solution will be exposed.

Besides, it is interesting to note how the heritage protection context affects in each case the architectonic definition of implemented projects regarding their constructive solutions, the selection of finishes and the preservation and restoration of elements.

Finally, this paper to provide both a general and precise vision in depth of the usual casuistic within interventions that address the improvement of accessibility conditions in historic buildings of the city of Barcelona, as well as other cities in which, similarly, historical centers and old residential buildings need to be actualized.

Palabras Clave: rehabilitación; accesibilidad; edificios históricos; rehabilitación funcional

Key words: rehabilitation; accessibility; heritage; functional refurbishment

\section{Introducción}

En el contexto de la ciudad de Barcelona, las mejoras en el campo de la accesibilidad han sido uno de los principales motores de la rehabilitación durante los últimos años. Con ellas, se buscaba un incremento de los estándares de calidad del parque habitacional, a base de intervenciones de rehabilitación, unas veces globales, incluyendo mejoras en la accesibilidad urbana (Sanfeliu y Martín, 2017) (Borja y Muixí, 2001) y mejoras en grupos de edificios (Ferrer y Fernando, 1993) y otras veces puntuales, a base de mejoras de iniciativa privada en edificios individuales. El presente artículo se centra en este último tipo de intervenciones realizadas en 


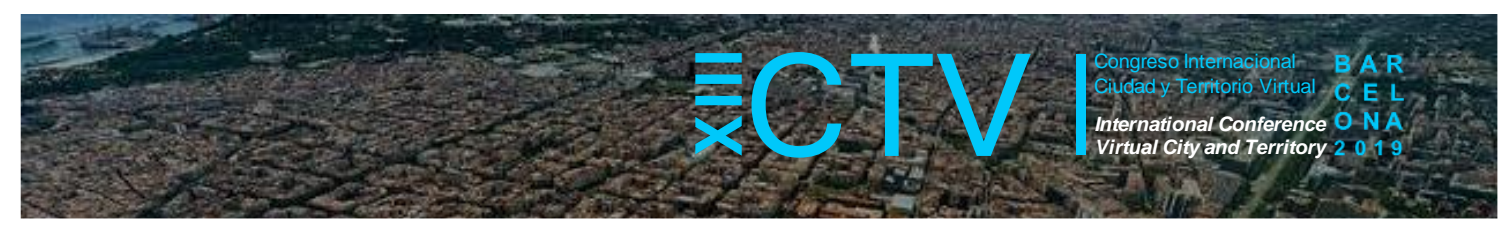

los edificios históricos de viviendas de la ciudad de Barcelona. Este tipo de edificios se encuentra en gran medida en el centro histórico de Barcelona o Ciutat Vella, en el Eixample y en los diferentes antiguos municipios del llano de Barcelona que fueron anexionados a la ciudad entorno al año 1900: Les Corts de Sarrià, Gràcia, Horta, Sant Andreu del Palomar, Sant Gervasi de Cassoles, Sant Martí de Porvençals, Santa Maria de Sants, Sarrià y Vallvidriera (figura 1). Dichos edificios se caracterizan por una construcción con técnicas tradicionales, con estructura de paredes de carga (de piedra, ladrillo o tierra) y forjados unidireccionales (con vigas de madera o acero y bovedillas cerámicas), pudiéndose considerar en esta categoría aquellos edificios construidos con anterioridad a 1940 (Cornadó y Martín, 2018).

Figura 1. Estado de la construcción del llano de Barcelona en 1890. Se pueden apreciar alrededor del núcleo antiguo los municipios que fueron agregados entre finales del siglo XIX y principios del XX y la incipiente construcción del Ensanche

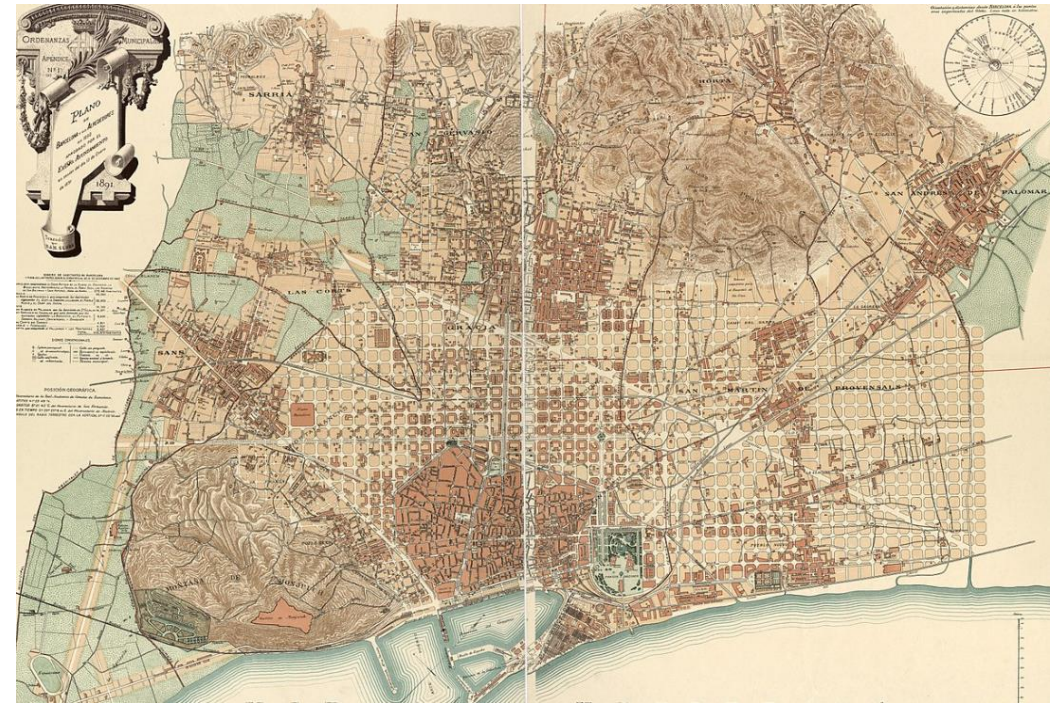

Fuente: Plano de Barcelona y sus alrededores en 1890, J.M. Serra. Wikipedia

Cabe destacar que la realidad física de los edificios en centros históricos ya consolidados requiere una especial atención a la hora de realizar cualquier tipo de obra de intervención. No son una excepción las obras de mejora de las condiciones de accesibilidad. Con dicha finalidad, las operaciones más frecuentes son la incorporación de ascensores y la realización de obras en los vestíbulos de acceso y cajas de escalera. La propia configuración urbana compacta de la ciudad condiciona la instalación de nuevos ascensores, que deben realizarse en el interior del edificio. Este hecho junto con las limitadas dimensiones habituales de los espacios comunes y patios de los edificios históricos generan ciertas dificultades proyectuales que pueden ser solventadas de diferentes maneras, tal y como se expondrá a continuación. A ello se deben añadir los requisitos normativos (CTE-DB-SUA, 2010) (LLEI 13/2014) (Norma OME, 2004) cada vez más exigentes y el grado de protección particular de cada edificio (Decret 141/2012). Asimismo, la particularidad de las ciudades españolas y del sur de Europa, donde el parque residencial existente es de forma casi exclusiva de propiedad privada y donde son muchas las comunidades residenciales de varios propietarios, añade complejidad y dificultad en la gestión de las intervenciones de mejora de accesibilidad, que suponen habitualmente costes elevados y la necesidad de formular acuerdos en la comunidad (Fundación ONCE y CGATE, 2018). 


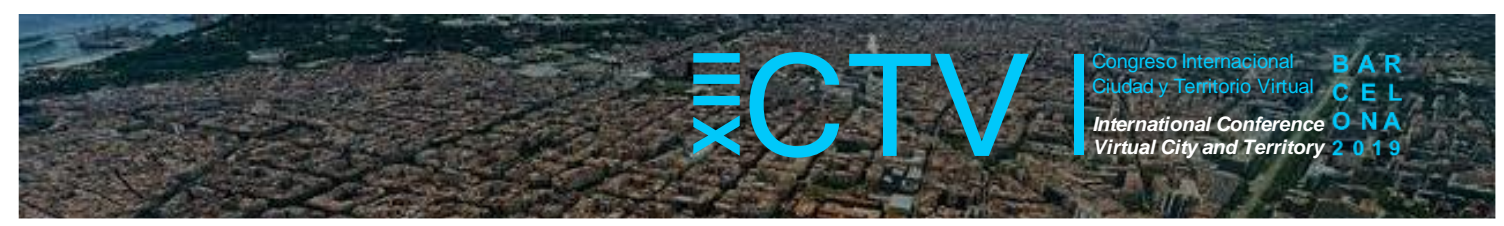

La concesión de subvenciones y ayudas a la rehabilitación en materia de mejora de la accesibilidad ha actuado como revulsivo en la proliferación de este tipo de intervenciones en centros históricos ya consolidados dejando un legado de repertorio de posibles soluciones que merecen ser estudiadas.

\section{Objetivos}

Los objetivos de la investigación que aquí se presenta son:

- La caracterización de las principales deficiencias de accesibilidad presentes en los edificios históricos de Barcelona y que pueden ser susceptibles de una mejora.

- La detección de las principales dificultades técnicas y morfológicas que se pueden dar en este tipo de edificios a la hora de proyectar una rehabilitación de mejora de la accesibilidad.

- El establecimiento de una serie de pautas para las intervenciones de mejora de accesibilidad más habituales en este tipo de edificios, a partir del estudio de intervenciones ya realizadas.

\section{Metodología}

En la presente contribución, se estudian un total de 20 proyectos realizados entre 2012 y 2019 , dentro del ámbito de estudio, destinados a mejorar la accesibilidad en edificios históricos plurifamiliares de titularidad privada de Barcelona. En la totalidad de casos, la intervención de rehabilitación incluye la instalación de un ascensor y, en muchos de ellos, la remodelación y adecuación de vestíbulos. Cabe decir que estas intervenciones comportan a menudo la realización de actuaciones complementarias como la resituación de instalaciones y cuartos de contadores, la sustitución o construcción de nuevos lucernarios o claraboyas, y actuaciones estructurales puntuales como aperturas de huecos en muro, refuerzos en forjados existentes y recortes y refuerzos de bóvedas de escalera.

Del total de edificios de la muestra 14 están ubicados en el Eixample, 3 en Ciutat Vella, 1 en Gràcia, 1 en Les Corts y 1 en Sants (ver listado en Tabla 1). De cada caso se estudian las deficiencias de accesibilidad que existían previamente a la realización del proyecto y las soluciones adoptadas de cara a su mejora estudiando los principales condicionantes de dichas soluciones.

\section{Principales deficiencias de accesibilidad de los edificios históricos de Barcelona}

En el protocolo de Inspección Técnica de Edificios (Real Decreto-ley 8/2011) y en referencia a la evaluación de las condiciones básicas de accesibilidad, se establece la siguiente división:

- deficiencias de accesibilidad respecto al exterior

- deficiencias de accesibilidad entre plantas del edificio

- deficiencias de accesibilidad en las plantas del edificio

- deficiencias de accesibilidad en plazas de parking

- deficiencias de accesibilidad en otros espacios de uso comunitario

Dadas las características morfológicas y constructivas de los edificios construidos anteriormente a la segunda mitad del siglo XX (Aballanet et al., 2000), se puede afirmar que las deficiencias en materia de accesibilidad en este tipo de edificios se concentran 


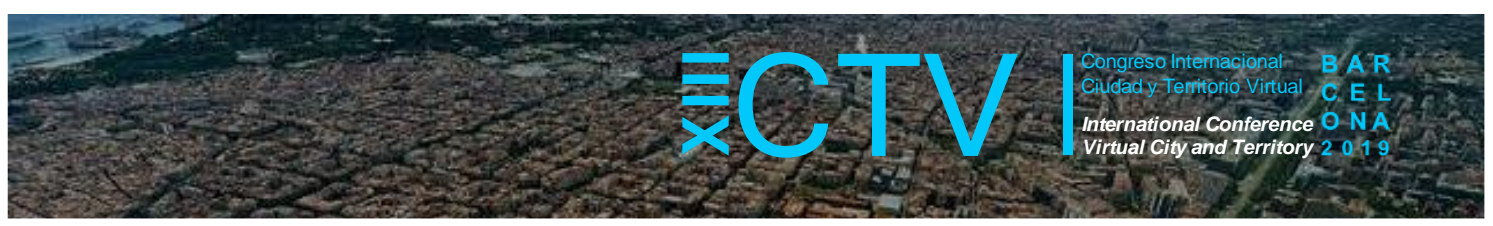

mayoritariamente en las tres primeras categorías de la lista anterior: deficiencias de accesibilidad respecto al exterior, deficiencias de accesibilidad entre las plantas del edificio y deficiencias de accesibilidad en las mismas plantas del edificio. De los edificios que forman la muestra de esta investigación, las deficiencias detectadas se presentan en la Tabla 1 y se describe la problemática concreta a continuación.

Tabla 1. Principales deficiencias iniciales en materia de accesibilidad en la muestra estudiada

\begin{tabular}{|c|c|c|c|}
\hline Emplazamiento & Respecto al exterior & Entre plantas & En las plantas \\
\hline Bordeus 9 & & $\mathrm{X}$ & $\mathrm{X}$ \\
\hline Bruc 80 & $\mathrm{X}$ & $\mathrm{X}$ & $\mathrm{X}$ \\
\hline Bruniquer 153 & & $\mathrm{X}$ & $\mathrm{X}$ \\
\hline Calabria 73 & $\mathrm{X}$ & & $X$ \\
\hline Casanova 72 & $\mathrm{X}$ & $\mathrm{X}$ & $\mathrm{X}$ \\
\hline Castillejos 168 & $\mathrm{X}$ & $\mathrm{X}$ & $\mathrm{X}$ \\
\hline Corcega 472 & & $\mathrm{X}$ & $\mathrm{X}$ \\
\hline Flor de Lliri 3 & $\mathrm{X}$ & $\mathrm{X}$ & $\mathrm{X}$ \\
\hline Mallorca 180 & $\mathrm{X}$ & $\mathrm{X}$ & $\mathrm{X}$ \\
\hline Moianès 51 & & $\mathrm{X}$ & $\mathrm{X}$ \\
\hline Muntaner 148 & & $\mathrm{X}$ & $\mathrm{X}$ \\
\hline Rocafort 102 & $\mathrm{X}$ & $\mathrm{X}$ & $\mathrm{X}$ \\
\hline Ronda Sant Pere 53 & & $\mathrm{X}$ & $X$ \\
\hline S. Antoni Ma. Claret 30 & & $\mathrm{X}$ & $X$ \\
\hline Santa Madrona 24 & $\mathrm{X}$ & $\mathrm{X}$ & $\mathrm{X}$ \\
\hline Tigre 33 & & $\mathrm{X}$ & $\mathrm{X}$ \\
\hline Valencia 365 & & $\mathrm{X}$ & $\mathrm{X}$ \\
\hline Valencia 489 & $\mathrm{X}$ & & $\mathrm{X}$ \\
\hline Viladomat 171 & & $\mathrm{X}$ & $\mathrm{X}$ \\
\hline Viladomat 193 & & $X$ & $X$ \\
\hline
\end{tabular}

Fuente: Elaboración propia

\subsection{Deficiencias de accesibilidad respecto al exterior}

Es habitual la presencia de uno o varios escalones justo en el acceso del edificio o en mitad del vestíbulo (Figura 2). Si bien actualmente se admite la existencia de un escalón aislado o dos consecutivos en las zonas comunes de los edificios de uso residencial (CTE-DB-SUA, 2010), el itinerario deja de ser accesible, existiendo para los edificios de obra nueva la exigencia de tener como mínimo un itinerario accesible que comunique el edificio con el exterior. Esta limitación en la accesibilidad edificio lleva con frecuencia a realizar obras de adecuación en los vestíbulos.

Figura 2: Ejemplos de deficiencias de accesibilidad con respecto al exterior: presencia de peldaños justo en la entrada del edificio y en los vestíbulos

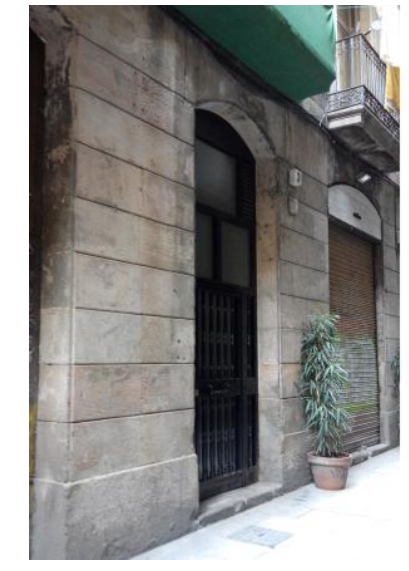

Fuente: Autoras
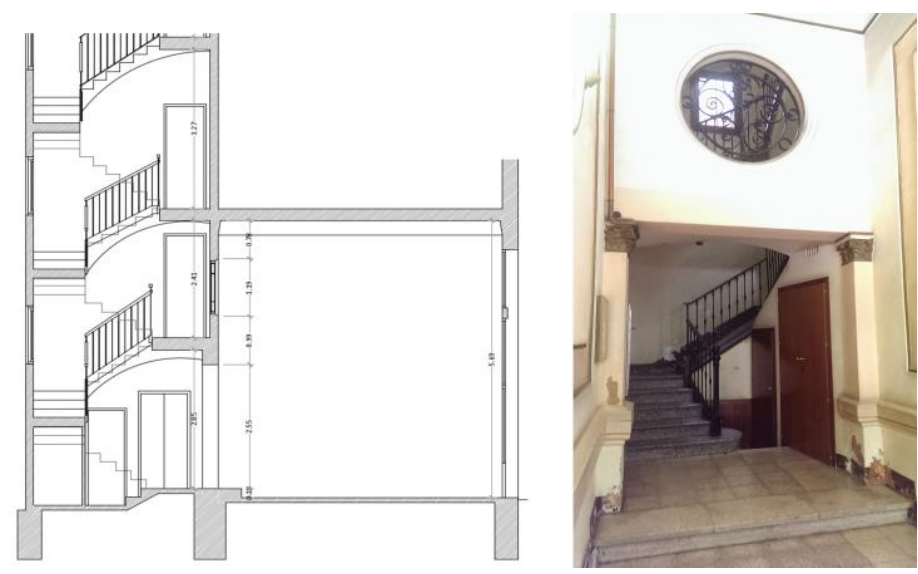


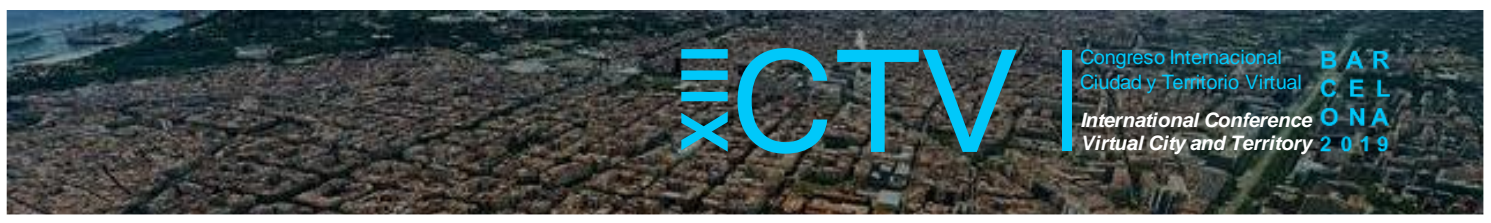

\subsection{Deficiencias de accesibilidad entre las plantas del edificio}

Actualmente, se exige a los edificios residenciales de obra nueva la instalación de un ascensor o rampa accesible siempre que éstos superen las dos plantas de altura (CTE-DB-SUA, 2010). Evidentemente, si se observa con esta óptica el parque habitacional construido (Figura 3), es evidente la falta de accesibilidad habitual entre plantas de los edificios de viviendas existentes. De hecho, la incorporación de un nuevo ascensor es la motivación mayoritaria en las obras de mejora de accesibilidad de los edificios de viviendas cuando éstos no disponen de él. En otros casos, la sustitución de un ascensor antiguo y las actuaciones que puede llevar asociada esta operación anima a los promotores a llevar a cabo otro tipo de mejoras de accesibilidad complementarias como la adecuación de los vestíbulos.

Otra deficiencia de accesibilidad habitual en los edificios históricos es la excesiva altura de los escalones existentes. Cuando esto ocurre y la escalera queda confinada entre muros de carga, la problemática tiene difícil solución, sobre todo si no se quiere invadir espacio privado de las viviendas ni que la intervención pase a tener un gran alcance estructural.

\subsection{Deficiencias de accesibilidad en las plantas del edificio}

En esta categoría el mayor número de deficiencias en materia de accesibilidad se dan por el reducido tamaño de los vestíbulos de acceso a las viviendas en los rellanos. Para un itinerario accesible es necesario disponer de un espacio de giro en los vestíbulos y delante del ascensor de 1,50m de diámetro, los pasos y pasillos deben ser, a su vez, de como mínimo 1,20m admitiendo estrechamientos puntuales. En el caso de los edificios históricos de la muestra, la mayoría de los vestíbulos de acceso a las viviendas no llegan a tener unas dimensiones suficientes como para poder trazar una circunferencia de $1,50 \mathrm{~m}$ de diámetro, rondando la mayoría de ellos el 1,20 de ancho. Una intervención que convierta en accesible un vestíbulo de acceso a las viviendas es una operación complicada sobre todo cuando los muros que cierran la caja de escalera forman un rectángulo de dimensiones reducidas y no hay posibilidad de ampliar los vestíbulos sin intervenir en la estructura.

Otra casuística que también ocasiona deficiencias de accesibilidad en las propias plantas del edificio es la existencia de forjados a diferente cota, que conllevan accesos a las diferentes viviendas de forma decalada, en diferentes rellanos de la escalera. Ninguno de los edificios de la muestra presenta esta circunstancia.

Figura 3. Ejemplos de deficiencias de accesibilidad entre las plantas de un edificio: falte de ascensor y rellanos y anchos de paso insuficientes
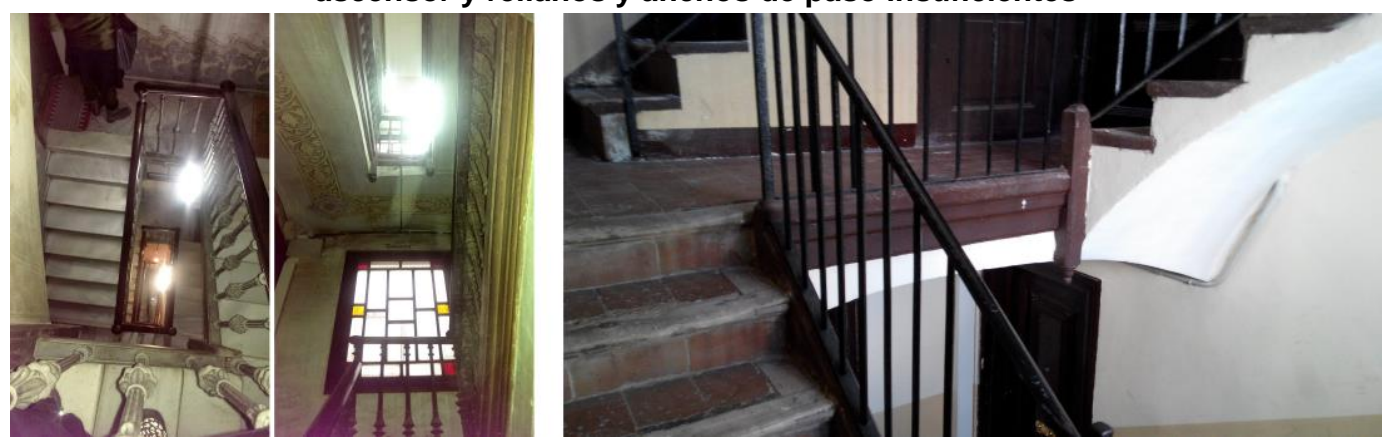

Fuente: Autoras 


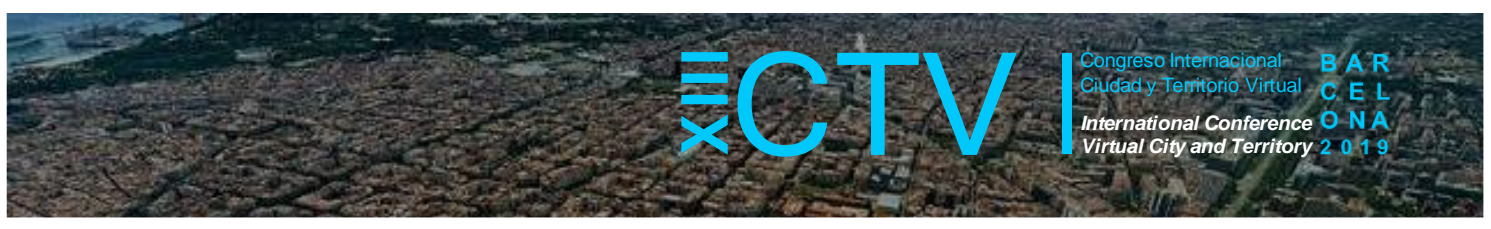

\section{Intervenciones para la mejora de la accesibilidad de los edificios}

Los siguientes apartados desarrollan las diferentes posibilidades proyectuales para las mejoras de la accesibilidad tanto desde el punto de vista morfológico como constructivo.

\subsection{Soluciones morfológicas}

Como se ha expuesto anteriormente, las intervenciones de rehabilitación para la mejora de las condiciones de accesibilidad en edificios históricos suelen incluir la instalación de un nuevo ascensor o sustitución del existente y, frecuentemente, obras en el vestíbulo para la supresión de barreras arquitectónicas. La tabla 2 especifica cuáles han sido las intervenciones en cada uno de los casos de la muestra.

En las actuaciones de instalación de un nuevo ascensor en un edificio histórico, el condicionante principal es la imposibilidad de disponer de las dimensiones suficientes como para poder albergar una caja de ascensor que permita tener una cabina, accesible $(1,10 \mathrm{~m} x$ $1,25 \mathrm{~m}$ como mínimo). En las operaciones de este tipo se puede admitir un ascensor de dimensiones más reducidas que las mínimas que se exigen para obra nueva, alegando una mejora en la accesibilidad existente y unas limitaciones técnicas que puedan hacer inviable otra opción. De forma general, existen dos formas mayoritarias de ubicar un ascensor en un edificio histórico de viviendas: en el hueco de escalera (Figura 4) o en un patio adyacente a la caja de escalera (Figura 5).

Tabla 2. Intervenciones para la mejora de la accesibilidad

\begin{tabular}{|c|c|c|c|}
\hline Emplazamiento & Intervención en el vestíbulo & Ascensor & Ubicación del ascensor \\
\hline Bordeus 9 & - & nuevo & patio \\
\hline Bruc 80 & supresión escalones & nuevo & hueco escalera \\
\hline Bruniquer 153 & - & nuevo & patio \\
\hline Calabria 73 & - & sustitución & hueco escalera \\
\hline Casanova 72 & nueva rampa & nuevo & hueco escalera \\
\hline Castillejos 168 & nueva rampa & nuevo & hueco escalera \\
\hline Corcega 472 & - & nuevo & patio \\
\hline Flor de Lliri 3 & ocupación local & nuevo & hueco escalera \\
\hline Mallorca 180 & recorte lateral escalera & nuevo & patio \\
\hline Moianès 51 & reubicación instalaciones & nuevo & patio \\
\hline Muntaner 148 & rampa & nuevo & patio \\
\hline Rocafort 102 & - & nuevo & patio \\
\hline Ronda Sant Pere 53 & - & nuevo & patio \\
\hline S. Antoni Ma. Claret 30 & - & nuevo & hueco escalera \\
\hline Santa Madrona 24 & reordenación y rampas & nuevo & patio \\
\hline Tigre 33 & - & nuevo & hueco escalera \\
\hline Valencia 365 & reubicación instalaciones & nuevo & patio \\
\hline Valencia 489 & reordenación generalizada & sustitución & patio \\
\hline Viladomat 171 & recorte lateral escalera & nuevo & hueco escalera \\
\hline Viladomat 193 & - & nuevo & patio \\
\hline
\end{tabular}

Fuente: Elaboración propia

Para la ubicación de un nuevo ascensor, con su cerramiento, en un hueco de escalera (Figura $4^{2}$ ), éste debe tener unas dimensiones suficientes que permitan el paso de la cabina y la previsión de unas holguras de funcionamiento y un espacio para disponer el cerramiento. Un espacio muy reducido de cabina limitará el número de personas que podrán usar el ascensor

${ }^{2}$ Se representará en amarillo los derribos y en rojo la obra nueva. 


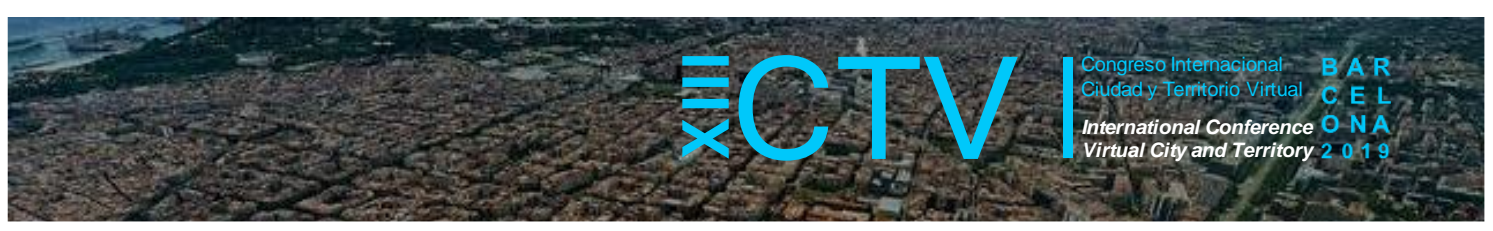

haciendo inviable esta opción. Los cerramientos de la nueva caja de ascensor suelen hacerse en soluciones ligeras, abundando los cerramientos de chapa perforada u opaca. En casos en los que el hueco de la escalera es insuficiente se puede recurrir al recorte y refuerzo de las bóvedas de escalera, teniendo en cuenta que el ancho de paso restante de escalera no puede ser inferior a $0,8 \mathrm{~m}$.

Otra posibilidad, es la instalación del nuevo ascensor en el patio adyacente a la caja de escalera (Figura 5). En este caso el factor determinante serán las dimensiones del patio ya que la colocación de un ascensor en él hace disminuir notablemente el volumen de aire del mismo, influyendo negativamente en las condiciones de iluminación y ventilación de las estancias que dan a él. Evidentemente, esta es una circunstancia a evitar, pero la imposibilidad de colocación del ascensor en otra ubicación hace que esta solución sea adoptada en muchos casos. El impacto del nuevo ascensor en el patio puede minimizarse mediante la elección de un cerramiento lo más diáfano posible, tal como se explica en el siguiente apartado.

Figura 4. Ubicación de un nuevo ascensor en el hueco de escalera

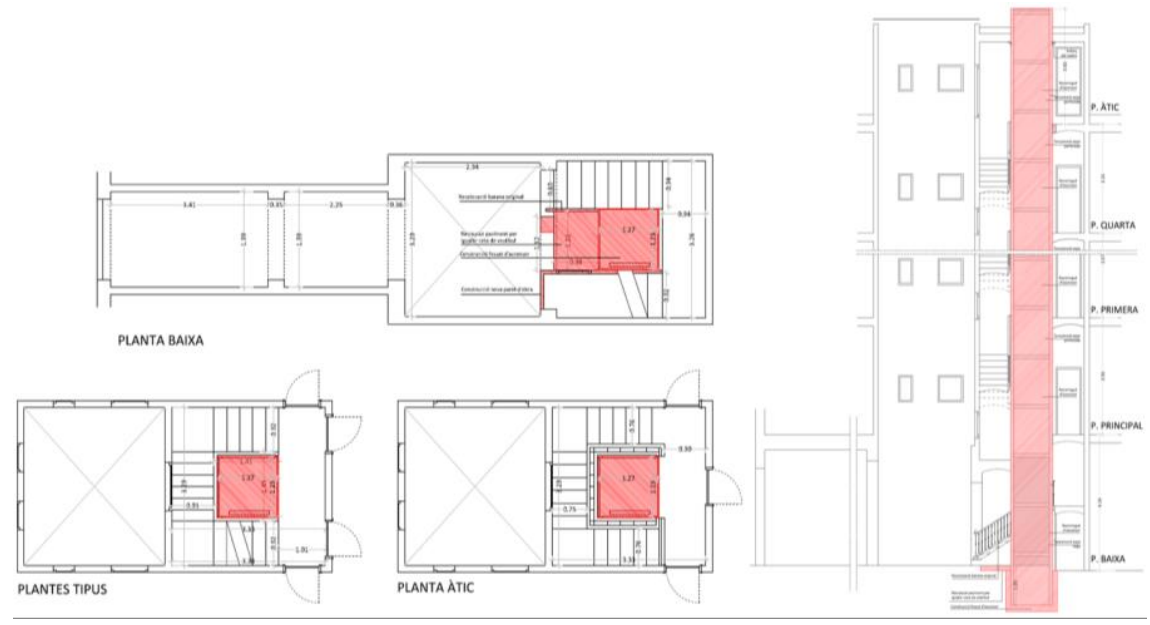

Figura 5. Ubicación de un nuevo ascensor en el patio adyacente a la caja de escalera

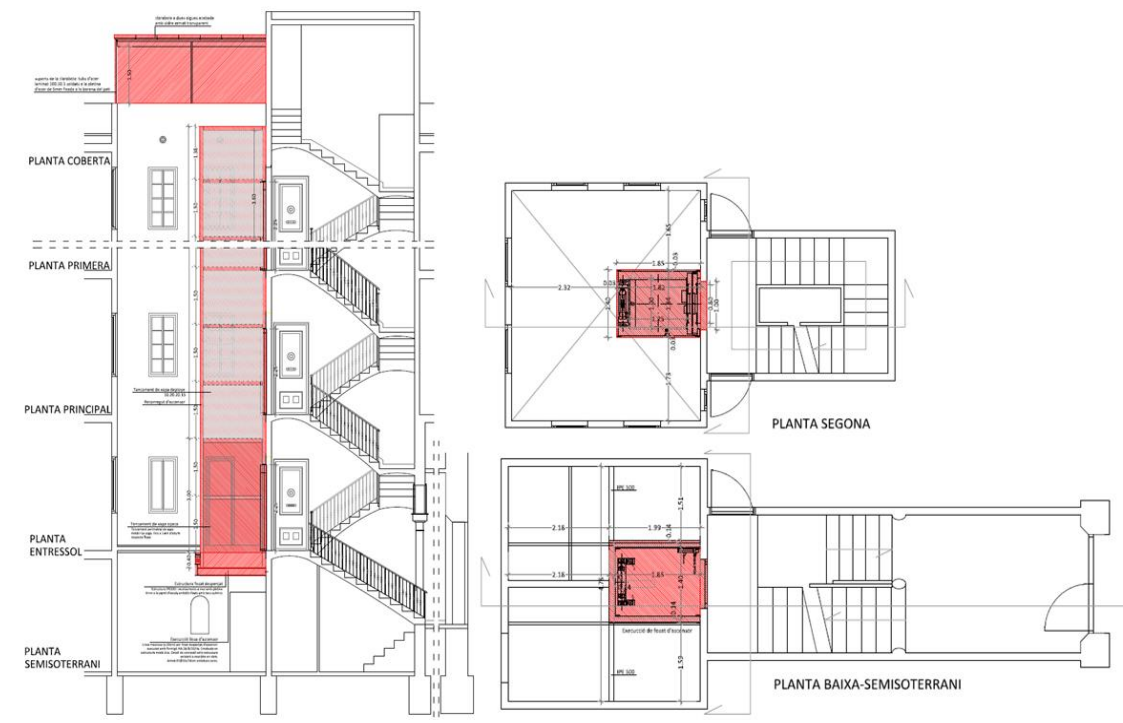

Fuente: Autoras 


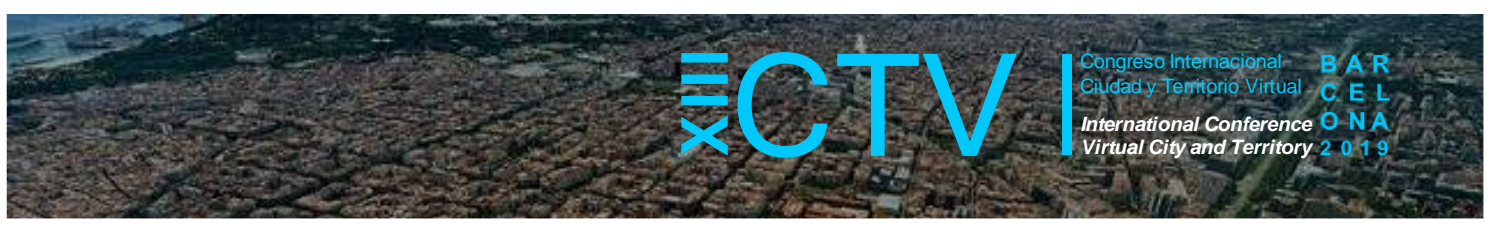

Como también se puede observar en la Figura 5, en algunos casos, la propia morfología del vestíbulo y la caja de escaleras hace que la única manera de colocar un ascensor si no se quiere ocupar espacio de las viviendas sea sacrificar un posible acceso a nivel desde planta baja. En esta casuística encontraremos ascensores que arrancan desde la primera planta de viviendas con la ejecución de un foso descolgado y su consiguiente actuación estructural. Otra circunstancia a tener en cuenta es la ventilación de la escalera ya que muy a menudo se aprovechan las ventanas de la caja de escalera para convertirlas en las puertas del ascensor. Este hecho hace que se reduzcan las condiciones de ventilación e iluminación de la escalera. Es por ello que, muy frecuentemente y cuando esto es posible, se suelen ampliar los huecos para incluir en ellos los desembarques del ascensor y una nueva ventana. Esta operación suele incluir la colocación de nuevos dinteles en la caja de escalera.

Por lo que se refiere a las posibles soluciones de mejora de la accesibilidad en los vestíbulos, se pueden dar diferentes soluciones para poder conseguir una entrada a nivel de calle. Esto dependerá de la configuración y dimensiones de éste, siendo el ancho del vestíbulo y la altura a salvar los factores más limitantes de cara a posibles reestructuraciones.

Una primera opción, factible cuando existe un escalón o dos en medio del vestíbulo, es una intervención que comporte el rebajado de la altura del vestíbulo y la agrupación de dichos escalones al primer tramo de escalera. Otra opción, es la supresión de escalones y su sustitución por rampas cuando las dimensiones del vestíbulo -sobre todo la longitud - lo permiten (Figura 6).

Figura 6. Intervenciones para un vestíbulo accesible. Iz. (fotografía) Agrupación de peldaño con primer tramo de escalera. Der. (plano) Construcción de nueva rampa
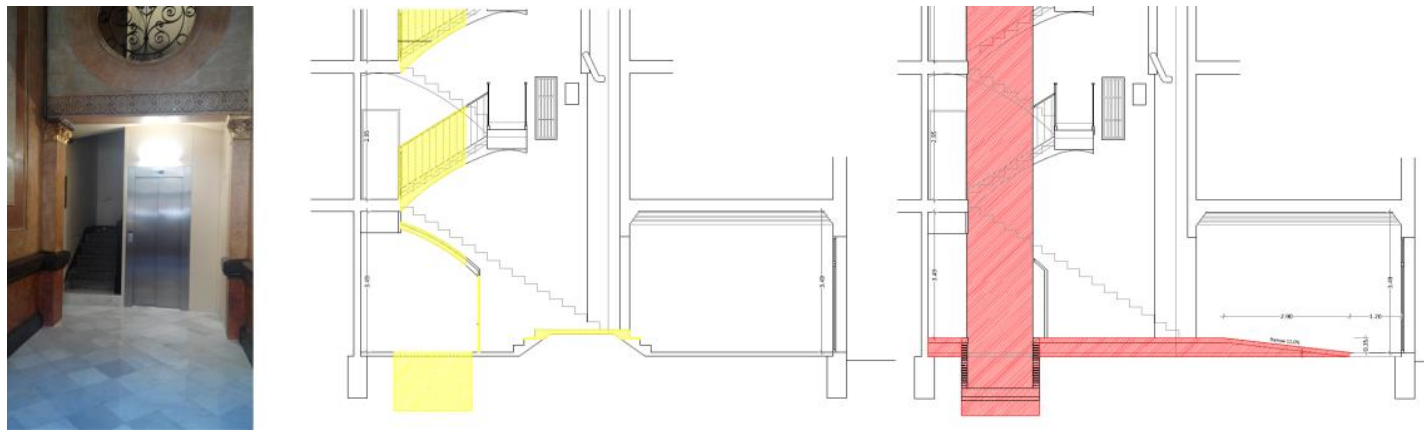

Figura 7. Reestructuración de vestíbulo
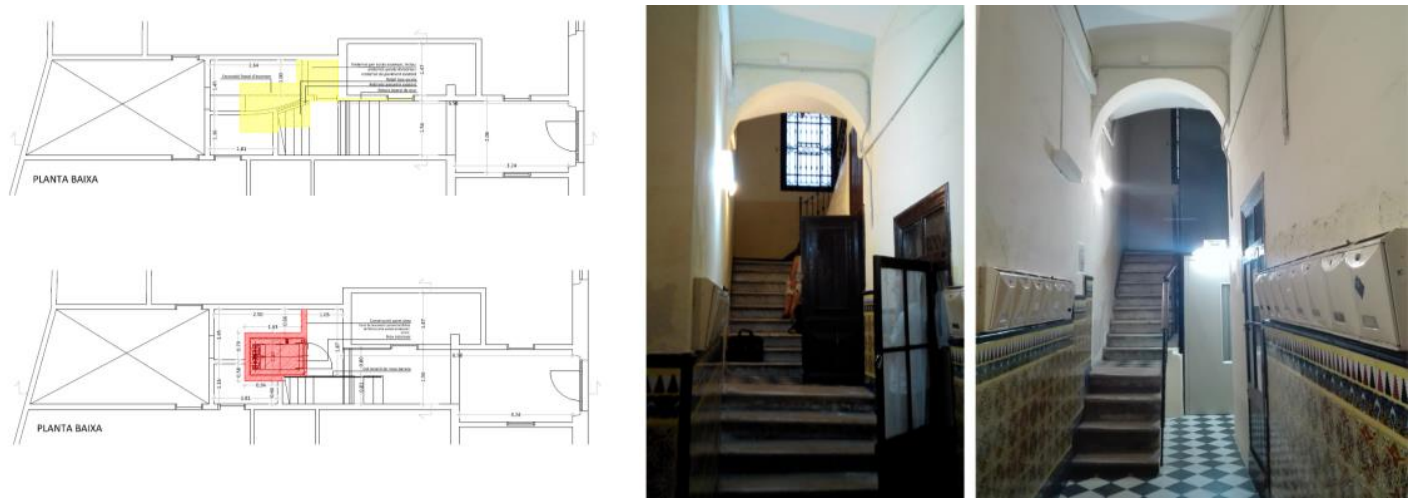

Fuente: Autoras 


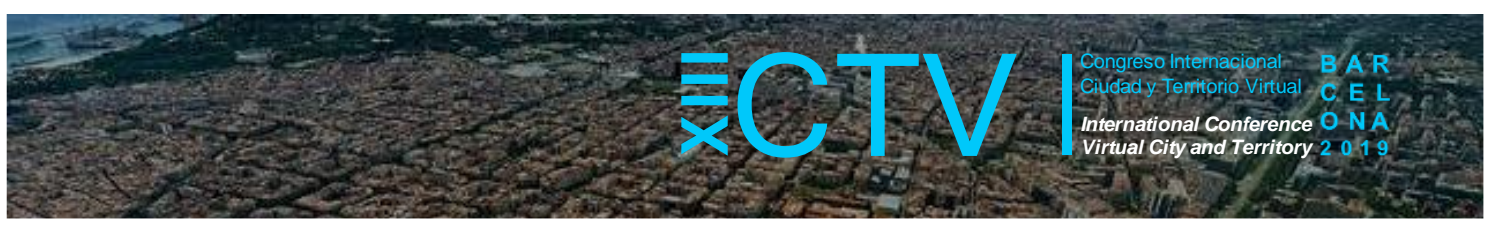

Otra opción, cuando sus dimensiones lo hacen viable, es la reestructuración del vestíbulo. Estas operaciones suelen comportar el recorte de algún tramo de escalera y una más que posible ocupación de superficie de los locales de planta baja para la que es necesario un acuerdo. En la Figura 7 se puede observar la reestructuración de un vestíbulo en el que se ha recortado una escalera dejando un tanto un ancho mínimo de paso como de escalera permitiendo un acceso al ascensor a cota de calle. Cabe mencionar que, a menudo, reestructuraciones de vestíbulo, tanto para suprimir barreras arquitectónicas como para permitir el acceso del nuevo ascensor situado en el patio, conllevan la reubicación de cuartos de instalaciones y la modificación de su trazado. Asimismo, vestíbulos que requieren de una intervención generalizada situados en edificios que gocen de protección patrimonial específica o bien estén situados en sectores de conservación específicos (Hernández-Cros y Moretó, 1987) serán instados a recuperar los materiales y soluciones constructivas originales.

\subsection{Soluciones constructivas}

La principal dificultad tecnológica de las intervenciones de mejora de las condiciones de accesibilidad en edificios históricos es la ubicación de un elemento tan invariable y condicionante como un ascensor y su cerramiento en un espacio de dimensiones reducidas, construido con técnicas y materiales históricos y con un estado de conservación variable. Es por ello que las soluciones constructivas que se mostrarán en este apartado se centran principalmente en la resolución de la caja de ascensor, sus encuentros, su cerramiento y su foso. En la Tabla 3 se muestran las principales soluciones constructivas que se han adoptado en los diferentes proyectos en referencia al tipo de foso, posibles recortes en bóvedas, intervenciones estructurales en muros, tipos de cerramiento para la caja de ascensor y posibles intervenciones en cubierta.

Tabla 3. Soluciones constructivas para la mejora de la accesibilidad.

\begin{tabular}{|c|c|c|c|c|c|}
\hline Emplazamiento & Tipo foso & $\begin{array}{l}\text { Recorte } \\
\text { bóvedas }\end{array}$ & $\begin{array}{l}\text { Intervenciones } \\
\text { en muros }\end{array}$ & $\begin{array}{c}\text { Tipo } \\
\text { cerramiento }\end{array}$ & $\begin{array}{c}\text { Intervenciones en } \\
\text { cubierta }\end{array}$ \\
\hline Bordeus 9 & excavado & - & Si & chapa perforada & nueva claraboya \\
\hline Bruc 80 & excavado & en p. tipo & - & chapa deployé & agujero cubierta \\
\hline Bruniquer 153 & excavado & en p. tipo & - & chapa perforada & \\
\hline Calabria 73 & se mantiene & - & - & original & \\
\hline Casanova 72 & excavado & - & - & chapa deployé & \\
\hline Castillejos 168 & excavado & en p. tipo & - & chapa perforada & \\
\hline Corcega 472 & descolgado & - & $\mathrm{Si}$ & vidrio & \\
\hline Flor de Lliri 3 & excavado & en p. tipo y pb & - & chapa deployé & Nuevo acceso a cubierta \\
\hline Mallorca 180 & excavado & en pb & Si & chapa deployé & nueva claraboya \\
\hline Moianès 51 & excavado & en $\mathrm{pb}$ & Si & chapa perforada & \\
\hline Muntaner 148 & excavado & - & $\mathrm{Si}$ & chapa deployé & nueva claraboya \\
\hline Rocafort 102 & excavado & - & - & chapa perforada & \\
\hline Ronda Sant Pere 53 & descolgado & - & Si & chapa deployé & nueva claraboya \\
\hline S. A. Ma. Claret 30 & excavado & en p. tipo & - & chapa deployé & \\
\hline Santa Madrona 24 & excavado & - & Si & chapa perforada & nueva claraboya \\
\hline Tigre 33 & excavado & en p. tipo & - & malla metálica & \\
\hline Valencia 365 & excavado & - & Si & chapa deployé & \\
\hline Valencia 489 & excavado & - & $\mathrm{Si}$ & chapa perforada & \\
\hline Viladomat 171 & excavado & en p. tipo y pb & - & chapa perforada & agujero cubierta \\
\hline Viladomat 193 & descolgado & - & Si & chapa perforada & \\
\hline
\end{tabular}

Fuente: Elaboración propia 


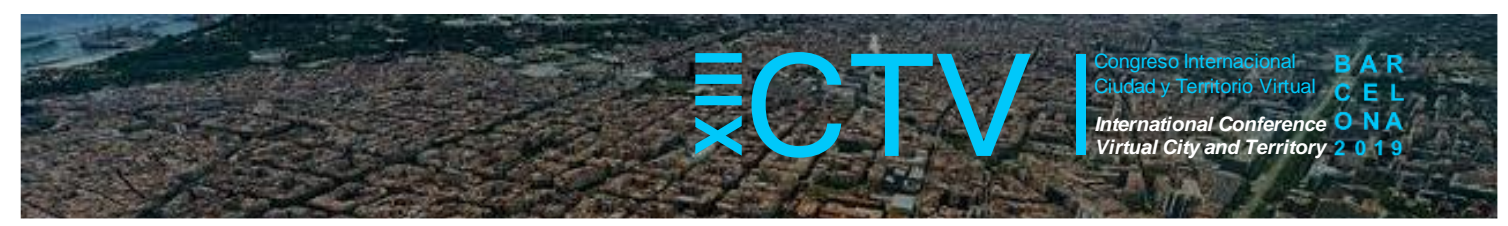

De forma general, la estructura del ascensor es una estructura tridimensional que puede resolverse con diferente tipo de perfiles, ya sea perfiles laminados o tubulares. La estructura de los ascensores de la muestra está construida a base de perfiles tubulares de acero y consta de cuatro perfiles longitudinales a modo de pilares y múltiples perfiles transversales que rigidizan la estructura y limitan la esbeltez de los perfiles de las esquinas. Dicha estructura se estabiliza en determinados puntos a la caja de escalera o patio, según sea el caso. La cimentación de la estructura suele ser una losa armada de hormigón que conforma el foso del ascensor y sobre la que arranca la estructura metálica. Las profundidades habituales de los fosos de ascensor oscilan entre $1 \mathrm{~m}$ i $1,30 \mathrm{~m}$, siendo el foso de $1,20 \mathrm{~m}$ el más habitual. No obstante, las posibles limitaciones de uso de las plantas bajas, hacen que en algunos casos se deba recurrir a la construcción de un foso descolgado con un foso compacto de menos de $30 \mathrm{~cm}$ de profundidad. Cuando esto ocurre, el foso descolgado se sustenta mediante una estructura en forma de $\mathrm{H}$ de perfiles metálicos anclados mediante placas y tacos químicos a las paredes de la caja de escalera o patio (ver Figura 8).

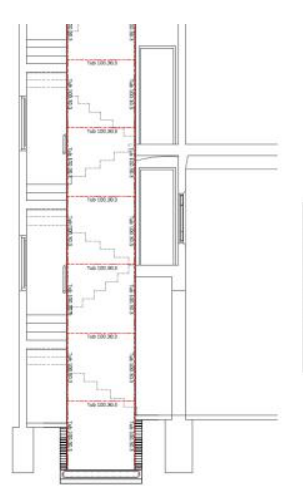

\section{Figura 8. Estructura de la caja y tipos de foso}

Nota: Izquierda: foso convencional. Derecha: foso descolgado

Fuente: autoras

Cuando el nuevo ascensor se sitúa en el hueco de escalera, a menudo se hacen necesarios recortes de las bóvedas de escalera y rellanos. En este caso, aunque se suele cortar las bóvedas longitudinalmente, es decir, en el sentido más favorable, para no disminuir su seguridad se recurre al refuerzo mediante perfiles metálicos que resiguen su desarrollo. Esta es la operación más frecuente, aunque cada caso puede presentar sus particularidades.

Otra circunstancia que puede darse cuando se coloca una caja de ascensor en un hueco de escalera, es que la altura de la caja de escalera sea insuficiente para albergar la altura de la caja del ascensor. Esto se debe a la distancia mínima de huida que deben presentar los ascensores entre su última parada y el cerramiento de la caja de ascensor. En algunos casos, la caja de ascensor debe perforar el último forjado de la caja de escalera ultrapasando la altura de cubierta (ver Figura 9 izquierda). Cuando esto se da se debe garantizar la seguridad estructural de este último forjado mediante refuerzos además de la estanqueidad de cubierta.

La conservación de la barandilla original suele ser uno de los requisitos del proyecto de incorporación de ascensor, en especial cuando hay requisitos patrimoniales. Al cerrarse el hueco de escalera con el cerramiento de la caja de ascensor no sería necesaria una barandilla, sino simplemente la colocación de un pasamano. No obstante, al tratarse de edificios históricos 


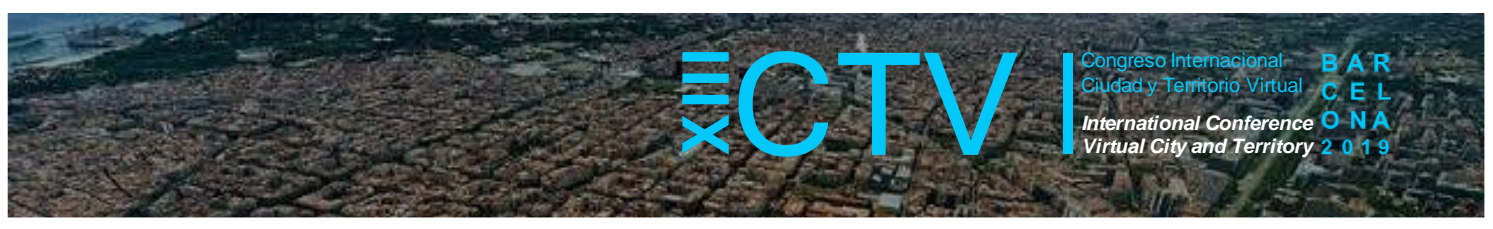

es común la reubicación de la barandilla original en su nueva posición, paralela al cerramiento de la caja de ascensor (ver ejemplos de la Figura 9).

Figura 9. De izquierda a derecha: caja de ascensor que atraviesa forjado de cubierta de caja de escalera y tres ejemplos de reubicación y conservación de barandillas
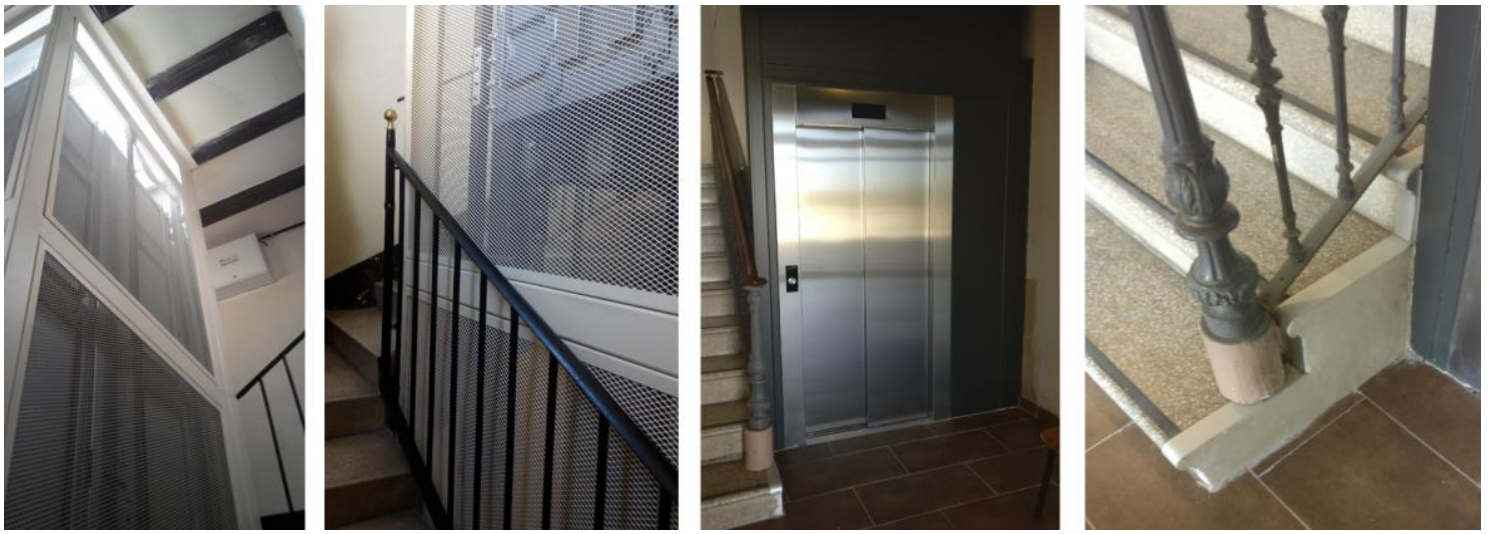

Fuente: autoras

Figura 10. Cerramientos de la caja de ascensor. De izquierda a derecha: chapa ciega, chapa "deployé", malla metálica y chapa perforada
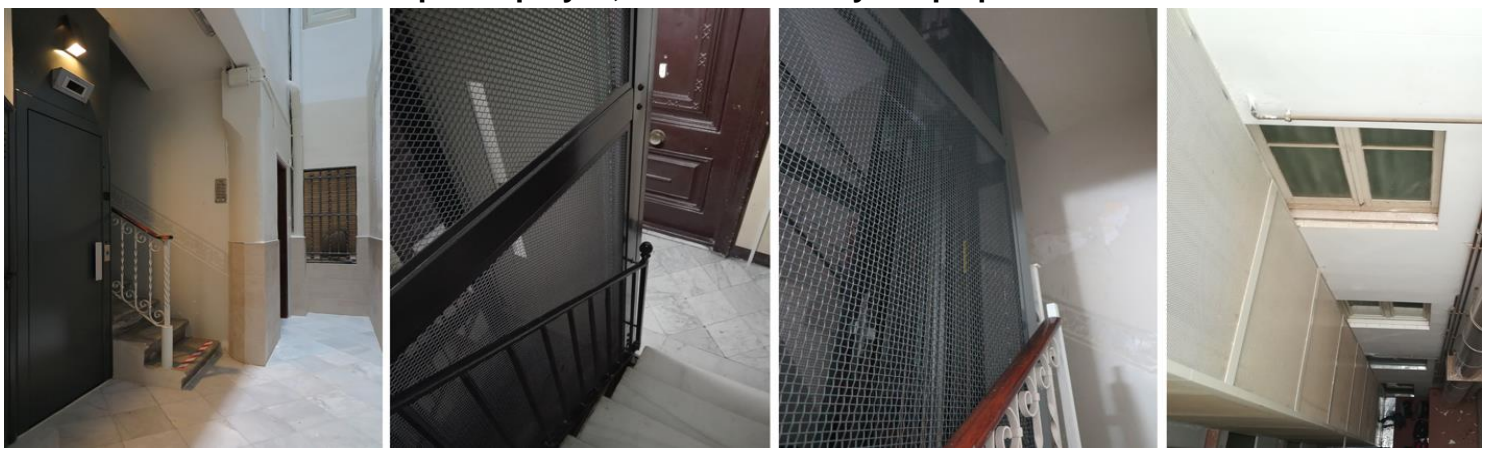

Fuente: autoras

Por lo que se refiere a los cerramientos de la caja de ascensor estos pueden ser variados. El primer requisito que deben cumplir es garantizar la seguridad del ascensor y sus usuarios y la no interferencia en su recorrido. También se exige a dicho cerramiento que no sea una barrera en el volumen de aire ni del patio ni de la caja de escalera y que permita el paso de la luz a través de él. Es por este motivo por el que se recurre muy a menudo a cerramientos de chapa perforada en diferentes variantes y de malla metálica. Cuando el nuevo ascensor se sitúa en un patio, éste debe estar cubierto mediante una claraboya si es que se busca un cerramiento de chapa perforada, ya que la maquinaria del ascensor y la cabina no deben mojarse. En los casos que esto ocurre, se puede valorar realizar un cerramiento de vidrio, siempre teniendo en cuenta que el volumen de aire del patio disminuirá en esta operación. Los cerramientos opacos suelen reservarse a las plantas bajas. En la figura 10 se pueden observar diferentes ejemplos de cerramiento de la caja de ascensor.

La colocación del nuevo ascensor en el patio adyacente a la caja de escalera puede requerir la construcción de un nuevo cerramiento superior del patio o la modificación del mismo (ver Figura 11). A menudo, los patios de los edificios históricos ya presentan algún tipo de cerramiento superior a modo de claraboya. Cuando la altura del nuevo ascensor supera la cota 


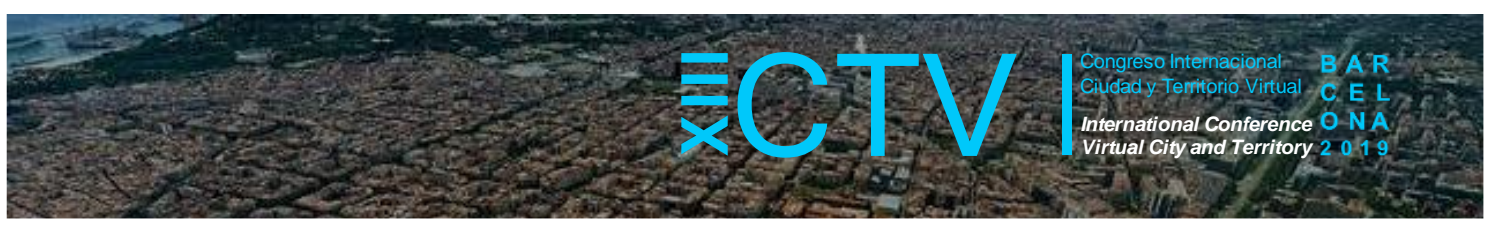

del lucernario original existen dos posibles opciones: la construcción de un nuevo lucernario a la cota conveniente o la elevación del lucernario existente a la nueva cota. En todos los casos se debe garantizar la iluminación del patio y su correcta ventilación.

Figura 11. Nuevo cerramiento superior de patio
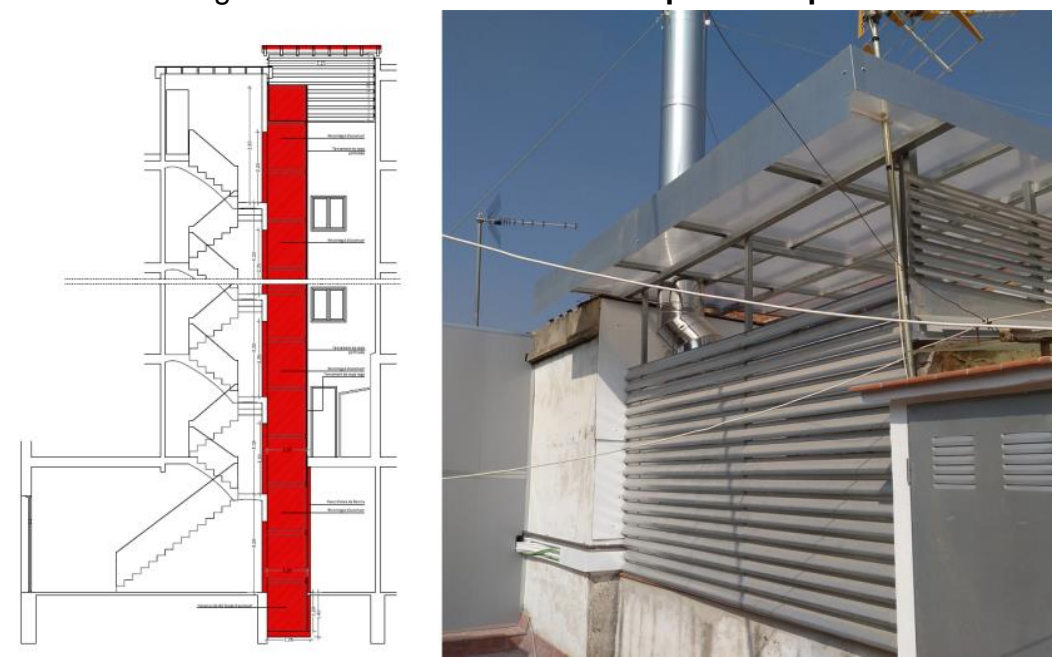

\section{Conclusiones}

El parque de edificios históricos de la ciudad de Barcelona presenta deficiencias en materia de accesibilidad y se puede afirmar que de forma generalizada no satisface los requisitos actuales en materia de accesibilidad. Los peldaños en la entrada o los vestíbulos, los edificios de más de dos plantas sin ascensor y los rellanos insuficientes son frecuentes. Cabe decir que la mayoría de operaciones de rehabilitación vienen motivadas por la voluntad de colocar un nuevo ascensor hecho que puede propiciar otro tipo de operaciones de mejora de la accesibilidad en vestíbulos de acceso.

Las principales dificultades para la adecuación de la accesibilidad de un edificio suelen ser más morfológicas que técnicas. El imperativo de tener que colocar el nuevo ascensor en zonas comunes y no mediante cesiones de zonas privadas hace que los espacios disponibles sean reducidos. Las dos ubicaciones principales escogidas para instalación del ascensor suelen ser el hueco de escalera y el patio adyacente a la caja de escalera. La primera de las dos presenta dificultades de espacio y frecuentes limitaciones en la medida de la cabina del ascensor que se puede instalar, además de necesitar frecuentes recortes y refuerzos de bóvedas de escalera. La segunda, implica la disminución de las condiciones de ventilación e iluminación de las estancias que dan al patio, pero es preferida cuando las dimensiones del hueco de escalera son escasas. A ello cabe añadir particularidades técnicas en los fosos de ascensor y en las soluciones de cubierta. Por último, cabe decir que en todo caso será determinante el grado de protección patrimonial del edificio que condiciona el tipo de cerramiento de la caja de ascensor y la recuperación de barandillas y vestíbulos.

Contribuciones de los autores: El trabajo se ha desarrollado de manera conjunta.

Conflicto de Intereses: Las autoras declaran que no hay conflicto de intereses. 


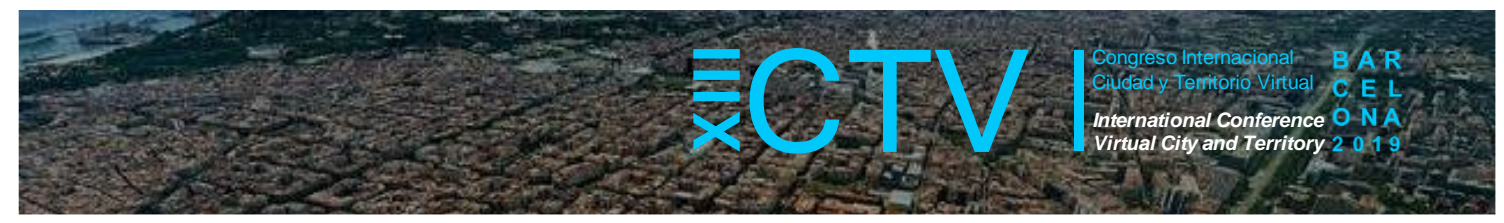

\section{Bibliografía}

Aballanet, A.; Castiñeira, I.; Montenys, X. y Paricio, A. (2000). Residència urbana a Barcelona 1945-1970. Barcelona, España: Ajuntament de Barcelona. Edicions UPC.

Borja, J. y Muxí, Z. (2001). L'espai públic: ciutat i ciutadania. Barcelona, España: Diputació de Barcelona, Oficina Tècnica de Cooperació.

Cornadó, C. y Martín, E. (2018). L'edifici plurifamiliar d'habitatges d'Elias Rogent a l'Eixample de Barcelona. En R. Dilla Martí y M. Torras Freixa. (Eds.), Elias Rogent i Barcelona. Arquitectura, patrimoni i restauració, pp. 59-74. Barcelona, España: Universitat de Barcelona Edicions.

Decret Accessibilitat GENCAT LLEI 13/2014, del 30 d'octubre, d'accessibilitat. BOE, núm. 281, del 30 de octubre de 2014, pp.94762-94805. Recuperado de: https://www.boe.es/eli/esct///2014/10/30/13/dof/spa/pdf

Decret 141/2012, de 30 d'octubre, pel qual es regulen les condicions mínimes d'habitabilitat dels habitatges i la cèdula d'habitabilitat. Diari Oficial de la Generalitat de Catalunya (DOGC), núm. 6245, del 02 de noviembre de 2012, pp. 1-69. Recuperado de: http://territori.gencat.cat/web/.content/home/01 departament/normativa i documentacio/docum entacio/habitatge millora urbana/habitatge/publicacions2/22 decret 141 2012/decret141 imp. $\underline{\mathrm{pdf}}$

Ferrer, M. y Fernando, J. (Ed.). (1993). La rehabilitació de l'Eixample 1987-1991. Barcelona, España: Ajuntament de Barcelona. Regidoria d'Edicions i Publicacions.

Fundación ONCE y Consejo General de la Arquitectura Técnica de España. (2018) ¿Cómo gestionar la accesibilidad? Comunidades de propietarios. Madrid, España: Fundación ONCE y Consejo General de la Arquitectura Técnica de España.

Hernàndez-Cros, J. E. y Moretó i Navarro, B. (1987). Catàleg del patrimoni arquitectònic històrico-artístic de la ciutat de Barcelona. Barcelona, España: Ajuntament de Barcelona, Edición a cargo del Servei de Protecció del Patrimoni Monumental.

Ley 38/1999 de 5 de noviembre, de Ordenación de la Edificación, de la que nace el Código Técnico de la Edificación. Documento Básico, Seguridad de Utilización y Accesibilidad (CTE$D B-S U A)$, de febrero de 2010, pp. 1-46. Recuperado de: https://www.codigotecnico.org/images/stories/pdf/seguridadUtilizacion/DBSUA.pdf

Normativa urbanística metropolitana, Ordenances metropolitanes d'edificació (OME). Títol II. Ordenances d'aplicació a tota la zona metropolitana, Capítol 1r. Condicions d'habitabilitat, de diciembre de 2004, pp. 404-430. Recuperado de: http://www.eca.es/servicios/OME Normativa Urbanistica Metropolitana.pdf

Real Decreto-ley 8/2011 fija la entrada en vigor de su artículo 21 (Obligatoriedad de la inspección técnica de edificios). Inspección Técnica de Edificios (ITEE). Artículo 21, BOE, núm. 161, del 7 de julio de 2011, pp. 71548-71586. Recuperado de: https://www.boe.es/eli/es/rdl/2011/07/01/8/dof/spa/pdf

Sanfeliu, I. y Martín, E. (2017). Public Space in Barcelona (1992-2017) - Evolution and Case Studies. IOP Conference Series: Materials Science and Engineering, 245 (052089), 01-11. DOI: $\underline{10.1088 / 1757-899 X / 245 / 5 / 052089}$ 